\title{
Phytochemical Constituents and Anti-inflammatory Activities of Momordicaaugustisepala Seed and Stem Species Grown in Nigeria
}

\author{
Ezekiel Gbadebo Adeyeni ${ }^{1,3,}{ }^{*}$, Ezekiel Temidayo Ayodele ${ }^{1}$, Taofik Adewale Adedosu ${ }^{1}$, \\ Olusola Nathaniel Majolagbe ${ }^{2}$, Ruth Adeola Adeyeni ${ }^{1}$ \\ ${ }^{1}$ Department of Pure and Applied Chemistry, LadokeAkintola University of Technology, Ogbomoso, Nigeria \\ ${ }^{2}$ Department of Pure and Applied Biology, LadokeAkintola University of Technology, Ogbomoso, Nigeria \\ ${ }^{3}$ Department of Chemistry, Hallmark University, Ijebu-Itele, Nigeria
}

Email address:

ezekieladeyeni@gmail.com (E. G. Adeyeni)

${ }^{*}$ Corresponding author

\section{To cite this article:}

Ezekiel Gbadebo Adeyeni, Ezekiel Temidayo Ayodele, Taofik Adewale Adedosu, Olusola Nathaniel Majolagbe, Ruth Adeola Adeyeni. Phytochemical Constituents and Anti-inflammatory Activities of Momordicaaugustisepala Seed and Stem Species Grown in Nigeria. Modern Chemistry. Vol. 8, No. 4, 2020, pp. 54-63. doi: 10.11648/j.mc.20200804.12

Received: November 2, 2020; Accepted: November 17, 2020; Published: December 31, 2020

\begin{abstract}
Diseases and infections are two of the most notable health challenges that humans are facing today; these have led to different health impairments, death and other economic damages. To combat these menaces, leaf and stem of Momordicaaugustisepala plant have been noted for their medicinal properties. Ethanol extract of Momordicaaugustisepala leaf and stem was investigated for their phytochemical constituents and antimicrobial activities. M. augustisepala leaf (MAL) andstem (MAS) was collected in Ogbomoso. Exactly $500 \mathrm{~g}$ of leafand stem was soaked in $4000 \mathrm{~mL}$ of ethanol. It was agitated for 1 hour at room temperature $\left(27^{\circ} \mathrm{C}\right)$ in ultrasonic sonicator based on their polarity. The extract was then decanted, combined, filtered and concentrated using Rotary Evaporator at $40^{\circ} \mathrm{C}$. The Fourier transforms infrared (FT-IR) spectra and ultravioletvisible (UV-VIS) spectrophotometer was obtained on a Perkin Elmer Spectrum and Varian Cary ultraviolet-visible. Results of the phytochemical analysis of the Momordicaaugustisepala leaf and stem showed the presence of Alkaloids, Glycosides, Flavonoids, Terpenoids, Tannins, Saponins, Phenols, Steroids and Anthraquinones, and Momordicaaugustisepala stem revealed, Alkaloids, flavonoids, Anthraquinones, Glycoside, Steroids, terpenoids, Tannins, Saponins and Phenols, while reducing sugar and phlobatanins were absent. Maximum inhibition protein denaturation of $86.6 \%$ and $89.3 \%$ was observed at $500 \mu \mathrm{g} / \mathrm{ml}$ for anti-inflammatory activities. As compared to Aspirin standard anti-inflammation drug which gave $85.9 \%$ at the same concentration. The results revealed that both seed and stem of M. augustisepala have potential for antimicrobial and antiinflammatory activities which may be due to the presence of plant secondary metabolites.
\end{abstract}

Keywords: Phytochemical Constituents, Antimicrobial Activity, Anti-inflammatory, Momordicaaugustisepala, Ethanol Extract

\section{Introduction}

Medicinal plants are the stronghold of some countries economy. About $80 \%$ of the global populace, mainly in urban and undeveloped countries relies on them for primary health care because of better compatibility, cultural acceptability, with fewer side effects in the human body [1]. The chemical compositions contained in herbal medicine are part of the physiological functions of living plant life and hence they are believed to have better matching with human body. Natural products from medicinal plants are widely used by the world to cure various diseases because they are very rich in bioactive constituents. The application of bioactive compounds derived from the medicinal plants is increasing tremendously, because the main pre-occupation with the use of artificial drugs is the adverse effect which can even be more hazardous to human wellbeing than the diseases they 
claim to cure [2]. In disparity, medicinal plants mainly used for medicines are based upon the fact that they contain natural substances that can abridge illness, promote good health and prove to be safe, have a good lenience with patient, globally competitive and relatively less. So, in respect to the curative power of medicinal plants, and revert to a natural remedy is a total obligation of our era [3]. Medicinal plants are the basic source of recent time medicine. Life has a source of medicinal agents for decades of years and an inspiring number of new drugs have been used for years in daily life to treat and cure many diseases globally. The use of medicinal plants to heal diseases can be found over decades as written documents for early civilization in India and some part of country [3]. Medicinal plants are traditional local drug with a very wilder advantage and global importance, the world is naturally blessed with abundance of medicinal plants. These herbs have always been a major source of medicines in countries like Nigeria, India, et.c and presently the herbal medicines havebecome known throughout the developed countries, as people struggling to treat illness with medicines, stay healthy in the face of pollution and chronic stress that work in concept with the body's own defence [4]. People in continents like America, Australia and Europe, have professional consultant in the herbal field that are using the plants for medicines. Mainly in parts of developing countries with few health facilities medicinal plants also play a vital role in the life of people living in the rural area [4]. The variety of medicinal plants with beneficial properties is fairly remarkable. It is expected that, about 70,000 plant species from flowering trees to lichens have been damaged at one time or another for the purpose of medicine. The herbs make available standing material for the synthesis or isolation of conservative drugs [5]. Plants geniuses are noticeable to have medicinal importance, over 5,700 traditional medicines were listed by Chinese Pharmacopoeia, and the majority of these are from plant basis. Although whole plants are not frequently used but over 500 medicinal plants are still engaged in conservative medicinal purposes. Through the past of mankind, many contagious diseases have been recognized to be treated with herbal medicine [6].

Herbal medicine plays a crucial function in health heed system of animals and human beings. These plants contain medicinal values due to substances present in different plant tissues. These substances used as atherapeutic agent or an active constituent for medical research are rich sources of bioactive compounds and thus serve as essential raw materials for drug production. These plants add substantially to health cultural veracity and local economy chiefly among the Yoruba, Hausa and Igbo tribes. The advantages of plants as basic solutions for the healing of diseases can be traced back to the earliest times. Because of its usual origin and minor side effects, the medicinal plant has been a significant growth in the field of herbal medicine [7]. For extraction of natural drugs, a broad range of medicinal plant parts like flower, fruit root, stem, twigs exudates and tailored plant organs have been used. Momordicaaugustisepala (Harmis) is a tropical vegetable locally known as (Ejirinnla). A monoecious scrambling herbaceous vine with slim Stem, very young plant, leaves sub orbicular, alternate, the blades are quite uneven in their sizes and are between 4-8 profound palmate lobes [8]. Fruits are 4.0-30.0 centimetre long, ovoid, spindle shaped usually ridged, dehiscent irregularly as a 4 valves fleshy capsule or flowers are unisexual, monoecious, tubular 6 lobed, moderate sized, yellow to oranges in colour, female flowers bracteates at the base with a fusiform and muricate ovary with brown Seeds of around 12.0-17.0 mm long, and male flower solitary. The plant has been used as cancer prevention, treatment of diabetes, fever etc [9].

\section{Materials and Methods}

\subsection{Plant Sample Collection and Identification}

The leaf and stem of Momordicaaugustisepala was collected in Ogbomoso around Laka Baptist Church area in the morning and evening for five days by transect method, on the November $11^{\text {th }}, 2016$ in Oyo State, South West Nigeria. The geographical location of the plant collection area is approximately at latitude $08^{0} \quad 8^{1} \quad 31.7940 " \mathrm{~N}$ and Longitude $4^{0} 4^{1} 42.6697 " \mathrm{E}$. Identification and authentication of the collected plant samples was carried out at the medicinal plant section of Forestry Research Institute of Nigeria (FRIN), Jericho, Ibadan, Oyo State. The herbarium number is FRI NO 382.

\subsection{Plant Sample Preparation}

The leaf and stem of M. augustisepala was air-dried, later pulverized into fine powder form with the aid of an electric kinelco blender and finally stored in a moisture free container.

\subsection{Reagents Used}

The analytical grade reagents used were purchased from Bristol Scientific Company, Sigma Aldrich.

\subsection{Plant Sample Extraction}

Exactly 500 grams of the leaf and stem was soaked in 4000 $\mathrm{mL}$ of ethanol. It was agitated for 1 hour at room temperature $\left(27^{\circ} \mathrm{C}\right)$ in ultrasonic sonicator based on their polarity. The crude extracts from the plants were then decanted, filtered and concentrated using rotary evaporator at $40^{\circ} \mathrm{C}$.

\subsection{Qualitative Phytochemical Screening of Plant Extracts}

Phytochemical analysis was carried out on the ethanolic Extract of $M$. augustisepala leaf and stem using standard procedure as described by Sofowora, Trease Evans and Harboneto screen for the presence of different classes of plant secondary metabolites and to recognize their phytochemical constituents [10-12].

\subsubsection{Alkaloids}

Four (4) $\mathrm{mL}$ of the test extracts was acidified with $1 \%$ aqueous hydrochloric acid $(\mathrm{HCl})$ on steam bath. Then, $1 \mathrm{~mL}$ of the acidified solution was treated with few drops of 
Meyer's reagent separately in different test tubes. Creamy white precipitate confirmed the presence of alkaloids. This confirmed Wagner's reagents (orange precipitate).

\subsubsection{Tannins}

Five drops of ferric chloride $\left(\mathrm{FeCl}_{3}\right)$ was added to $2 \mathrm{~mL}$ of each extracts solution, dirty green precipitate was observed which confirmed the presence of tannins.

\subsubsection{Anthraquinones}

Five (5) $\mathrm{mL}$ of the extracts was separately boiled with $10 \%$ hydrochloric acid $(\mathrm{HCl})$ for 10 minutes in water bath at $100^{\circ} \mathrm{C}$. The solution was then allowed to cool, then equal amount of trichloromethane $\left(\mathrm{CHCl}_{3}\right)$ was mixed with the filtrate and $10 \%$ of ammonia $\left(\mathrm{NH}_{3}\right)$ solution was also added to the mixture and heated. Then the formation of rose-pink colour from the solutionconfirmed the presence of anthraquinones.

\subsubsection{Glycosides}

Five (5) $\mathrm{mL}$ of $50 \%$ sulfuric acid was mixed with each test extract in a separate test tube. The mixture was heated in boiling water for 15 minutes. Fehling's solution was added and the resulting solution was then heated to boil. A brick-red precipitate confirmed the presence of glycosides.

\subsubsection{Reducing Sugars}

Distilled water was added separately to the extracts in the test tube and then shaken vigorously before filter. The filtrate was then boiled with drops of Fehling's solution A and B for 10 minutes. Orange-red precipitate was observed, which confirmed the presence of reducing sugars.

\subsubsection{Saponins}

Five (5) $\mathrm{mL}$ of distilled water was added to $2 \mathrm{~mL}$ of the extracts, shaken vigorously and heated to boil. Occurrence of frothing (appearance of creamy mixed with small bubbles) showed the presence of saponins.

\subsubsection{Flavonoids}

Four (4) $\mathrm{mL}$ of aqueous Sodium hydroxide $(\mathrm{NaOH})$ was added to $2 \mathrm{~mL}$ of each extract in separate test tubes. A yellow solution that turns colourless on addition of hydrochloric acid $(\mathrm{HCl})$ confirmed the presence of flavonoids.

\subsubsection{Phlobatanins}

Five (5) $\mathrm{mL}$ of extracts was dissolved in distilled water and then filtered. The filtrate was then boiled with $2 \%$ of hydrochloric acid $(\mathrm{HCl})$ solution. The appearance of red precipitate solution confirmed the presence of phlobatanins.

\subsubsection{Steroids}

To $1 \mathrm{~mL}$ of each test extract solution, 5 drops of concentrated sulfuric acid $\left(\mathrm{H}_{2} \mathrm{SO}_{4}\right)$ was added. A brownish to red colour was observed which confirmed the presence of steroids.

\subsubsection{Terpenoids (SalkowskiTest)}

Two (2) $\mathrm{mL}$ of chloroform $\left(\mathrm{CHCl}_{3}\right)$ and $3 \mathrm{~mL}$ of concentrated sulfuric acid $\left(\mathrm{H}_{2} \mathrm{SO}_{4}\right)$ was carefully added to $2 \mathrm{~mL}$ of each extracts to form a layer. A reddish - brown colouration of interface was formed confirmed the presence of terpenoids.

\subsubsection{Phenolic}

Exactly four drops of ferric chloride solution was added to $5 \mathrm{~mL}$ of the extracts. A formation of bluish - black colour confirmed the presence of phenols.

\subsection{Quantitative Phytochemical Screening of the Plant Extracts}

\subsubsection{Alkaloids}

Five (5) grams of each sample was weighed into a $250 \mathrm{~mL}$ erlmayer flask, $200 \mathrm{~mL}$ of $20 \%$ acetic acid in ethanol were mixed, and the solution was agitated for 20 minutes in ultrasonic sonicator. It was filtered and the extracts were concentrated on a water bath to one quarter $\left(\frac{1}{4}\right)$ of the original volume. Concentrated ammonia solution was added by drop wise to the extract until the precipitation was complete. The whole solution was allowed to settle and the precipitate was collected by filtration. The residue was the alkaloid, which was dried and weighed.

\subsubsection{Flavonoids}

Ten (10) grams of plant sample was repeatedly extracted with $100 \mathrm{~mL}$ of $80 \%$ aqueous methanol and agitated for 20 minutes in ultrasonic sonicator at room temperature. The mixture was filtered through a Whatman No $42(125 \mathrm{~mm})$ filter paper into a pre-weighed $250 \mathrm{~mL}$ flask. The filtrate was then transferred into a water bath and allowed to evaporate to dryness then the weight of the sample and the percentage quantity were then calculated.

\subsubsection{Total Phenols}

The fat free sample was prepared by soaking 2 grams of each sample in $100 \mathrm{~mL} \mathrm{n}$ - hexane. It was then agitated for 20 minutes at room temperature in ultrasonic sonicator. The filtrates were discarded and the residue was extracted in 50 $\mathrm{mL}$ diethyl-ether. It was then filtered into a separating funnel and about $50 \mathrm{~mL}$ of the $10 \%$ sodium hydroxide $(\mathrm{NaOH})$ solution was added. The mixture was shaken vigorously to separate the aqueous layer from the organic layer; $25 \mathrm{~mL}$ of distilled water was added. The total aqueous layer was acidified to $\mathrm{pH} 4.0$ by adding $10 \%$ hydrochloric acid $(\mathrm{HCl})$ solution and $50 \% \mathrm{~mL}$ dichloromethane (DCM). The organic layer was then collected, dried and then weighed.

\subsubsection{Tannins}

Five (5) grams of each of the grinded sample was weighed into a conical flask and $100 \mathrm{~mL} 2 \mathrm{M}$ hydrochloric acid ( $\mathrm{HCl})$ added. The content was boiled on a water bath for 30 minutes. The filtrate was then taken up twice in $40 \mathrm{~mL}$ of diethyl ether. The ether extract was heated to dryness and weighed.

\subsubsection{Saponins}

Five (5) grams of each sample was weighed and dispersed in $100 \mathrm{~mL}$ of $20 \%$ ethanol. The suspension was heated over a hot water bath for 4 hours with continuous stirring at about $55^{\circ} \mathrm{C}$, the sample mixture was filtered by using Whatman No 1 filter paper and the residue was re- extracted with another 
$100 \mathrm{~mL}$ of $20 \%$ ethanol. The combined extracts were reduced to $40 \mathrm{~mL}$ using water bath at about $100^{\circ} \mathrm{C}$, the concentrated solution was transferred into a $250 \mathrm{~mL}$ separating funnel and $20 \mathrm{~mL}$ of diethyl ether was added and shaken vigorously. The aqueous layer was recovered while the ether layer was discarded. The process was repeated; $30 \mathrm{~mL}$ of solvent (nbutanol) was added. The combined extracts were washed twice with $10 \mathrm{~mL}$ of $5 \%$ aqueous sodium chloride. The remaining solution was heated in a water bath, which was later evaporated. The sample was dried in an oven to a constant weight and the saponins content was calculated.

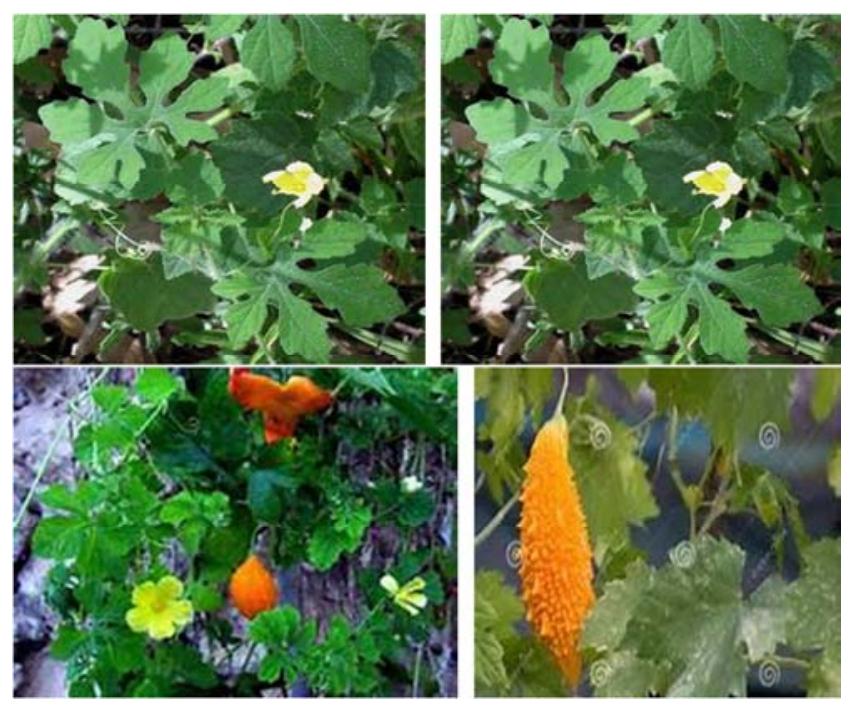

Figure 1. Pictues of Momordicaaugustisepala.

\subsection{Collection and Maintenance of Test Microbes}

Three (3) Gram negative and one Gram positive (1) bacteria with one fungus namely: Klebsiellapneumoniae, Escherichia coli, Pseudomonas aeruginosa, Staphylococcus aureus, and Candida albicans were used in this research. The test microbes were obtained from stock cultures in the Department of Microbiology, LAUTECH Teaching Hospital, Ogbomoso, Oyo State, Nigeria. The organisms were maintained on agar slant on McCartrey bottles and kept in the refrigerator prior to sub culturing at $4^{\circ} \mathrm{C}$.

\subsection{Antimicrobial Activity of Extracts Against Selected Microorganisms}

Receptiveness analyses were carried out using modified agar well diffusion method Garrod [13] and Trease [11] to investigate the antimicrobial activities of the extracts. The medium used was diagnostic sensitivity agar. The cultures were prepared in triplicates and incubated at $37^{\circ} \mathrm{C}$ for 24 hours. Exactly $0.2 \mathrm{~mL}$ of the broth culture of the test bacteria and fungus was kept in a sterile Petri-dish and $18 \mathrm{~mL}$ of the sterile molten diagnostic sensitivity agar was added. Holes were bored into the medium using sterile cork-borer, while $50 \mu \mathrm{L}$ of the extracts (ethanol) was added. These extracts were dissolved in the solvent used for extraction. Streptomycin was used as standard agent at a concentration of $1 \mathrm{mg} \mathrm{ml}^{-1}$. The plates were incubated at $37^{\circ} \mathrm{C}$ for $18-24$ hours and the diameters of the zones of inhibition of microbial growth were measured on the plates in millimeter. The Minimum Inhibitory Concentration (MIC) of each of the extracts was determined.

\section{Results and Discussion}

Table 1 revealed that the percentage composition of plant extracts of $M$. augustisepala leaf and stem crude extracts which are $90.70 \%$ and $88.82 \%$ respectively. These results showed that the plant under study is abundantly rich in phyto constituents, and the best solvent for extractions is ethanol. In ethanolic extract of M. augustisepala leaf and Stem, alkaloids, glycosides, terpenoids, flavonoids, tannins, saponins, phenols, steroids and anthraquinones were present while reducing sugar and phlobatanin were absent. This result showed that, MALand MASwere found to be very rich in phyto constituents and the best solvent for extraction according to this research work is ethanol because of their potency and medicinal values, which could be attributed to the presence of plant secondary metabolites which was found to be polar in nature.

Table 1. Percentage yield of the extracts of MAL and MAS.

\begin{tabular}{llll}
\hline Plant & Extract Coding & Solvent Used & \% yield \\
\hline Momordicaaugustisepala leaf & MAL & Ethanol & 90.70 \\
Momordicaaugustisepala stem & MAS & Ethanol & 88.82 \\
\hline
\end{tabular}

A phytochemical constituent, both quantitative and qualitative activities of MAL and MAS were carried out using ethanol as solventanalysis. Momordicaaugustisepala leaf showed the presence of Alkaloids, Glycosides, Flavonoids, Terpenoids, Tannins, Saponins, Phenols, Steroids and Anthraquinones, and Momordicaaugustisepala stem revealed, Alkaloids, flavonoids, Anthraquinones, Glycoside, Steroids, terpenoids, Tannins, Saponins and Phenols, while reducing sugar and phlobatanins were absent. Table 3 reports the results of quantitative estimation of plant secondary metabolites present in the extracts. A quantitative phytochemical analysis was carried out on the extracts to identify the constituents present. The quantities of phyto constituents are as follows alkaloids $(0.2370 \pm 0.04 \mathrm{mg} / \mathrm{g})$, flavonoids $(0.5300 \pm 0.04 \mathrm{mg} / \mathrm{g})$, phenol $(0.3967 \pm 0.12 \mathrm{mg} /$ $g)$, tannins $(0.6667 \pm 0.02 \mathrm{mg} / \mathrm{g})$ and saponins $(0.3433 \pm 0.24 \mathrm{mg} / \mathrm{g})$ Also, Alkaloids $(0.2467 \pm 0.02 \mathrm{mg} / \mathrm{g})$, flavonoids $(0.4260 \pm 0.02 \mathrm{mg} / \mathrm{g})$, phenol $(0.2800 \pm 0.03 \mathrm{mg} /$ $g)$, tannins $(0.2270 \pm 0.13 \mathrm{mg} / \mathrm{g})$ and saponins $(0.3466 \pm 0.03 \mathrm{mg} / \mathrm{g})$ respectively. A high quantity of Tannins, Flavonoids, Saponins, Alkaloids and Phenolic compound was found in MAL and MAS. The quantities of phyto constituents present in the extracts were alkaloids $(0.2370 \pm 0.04 \mathrm{mg} / \mathrm{g})$, flavonoids $(0.5300 \pm 0.04 \mathrm{mg} / \mathrm{g})$, 
phenol $(0.3967 \pm 0.12 \mathrm{mg} / \mathrm{g})$, tannins $(0.6667 \pm 0.02 \mathrm{mg} / \mathrm{g})$ and saponins $(0.3433 \pm 0.24 \mathrm{mg} / \mathrm{g})$. For MAL Also, alkaloids $(0.2467 \pm 0.02 \mathrm{mg} / \mathrm{g}), \quad$ flavonoids $(0.4260 \pm 0.02 \mathrm{mg} / \mathrm{g})$, phenols $(0.2800 \pm 0.03 \mathrm{mg} / \mathrm{g})$, tannins $(0.2270 \pm 0.13 \mathrm{mg} / \mathrm{g})$ and saponins $(0.3466 \pm 0.03 \mathrm{mg} / \mathrm{g})$ for MAS. This might be responsible for the anti-inflammatory activities of the plants [14]. This might also be the reason why $M$. augustisepala leaf and stem are used in the treatment of wound, burns and ulcer in herbal medicine. The tannins content was found to be $(0.666 \pm 0.02 \mathrm{mg} / \mathrm{g}$, $0.2270 \pm 0.13 \mathrm{mg} / \mathrm{g}$ and $0.160 \pm 0.03 \mathrm{mg} / \mathrm{g})$. Herbs that have tannins as their main components are astringent in nature and are used for treating intestinal disorders such as diarrhea and dysentery [15]. Thus exhibiting antimicrobial activities. Some of the largest groups of chemical produced by plants are Tannins, Flavonoids, Saponins and Phenolic and alkaloids and their amazing effects on humans have led to the development of powerful pain killer medicators [16]. These results showed that the plant under study is abundantly rich in phyto constituents. The FT-IR absorption spectrums were carried out to recognize the functional groups in pure compounds which can assist the structural elucidation and identification of bioactive compound, and the possible ones responsible for medicinal properties of the plant under study. The FT-IR spectrum (Tables 6 and 7) revealed the presence of hydroxyl, ester, and olefin, and ketones. By absorption, the prominent peaks obtained were $3378.15 \mathrm{~cm}^{-1}(\mathrm{O}-\mathrm{H}$ of hydrogen bonding str.), $3053.52 \mathrm{~cm}^{-1}$ (=C-H alkenes str.), $2928.21 \mathrm{~cm}^{-1}$ (C-H aliphatic str.), $1730.15 \mathrm{~cm}^{-1}(\mathrm{C}=\mathrm{O}$ of esther str.), $1716.16 \mathrm{~cm}^{-1}$ ( $\mathrm{C}=\mathrm{O}$ of ketones str. $), 1616.44 \mathrm{~cm}^{-1}$ ( $\mathrm{C}=\mathrm{C}-\mathrm{C}$ alkanes str.), $1460.00 \mathrm{~cm}^{-1}, 1373.03 \mathrm{~cm}^{-1}\left(\mathrm{CH}_{3}\right.$ of methylene str.), $1099.91 \mathrm{~cm}^{-1}$ (C-O of ether str.), and 896.00 $\mathrm{cm}^{-1}$ (C-H bend vibration of alkanes). These peaks indicated the abundance of plant secondary metabolites which are medicinal in nature such as; Alkaloids, flavonoids, steroids, phenolic, tannins, saponins e.t.c. that supported the presence of these phyto constituents in the plants of study. From the UV-visible, the pure compound showed a maximum absorbance ranging from $242 \mathrm{~nm}$ to $424 \mathrm{~nm}$ which could be traced to organic compounds such as: $\mathrm{R}-\mathrm{OH}, \mathrm{R}-\mathrm{O}-\mathrm{R}, \mathrm{R}_{2} \mathrm{C}$ $\mathrm{CR}_{2}, \mathrm{R}_{2} \mathrm{CO}$ and $\mathrm{RCOOR}$. The results of antimicrobial screening of the crude extractsMAL and MAS are shown in Table 4 below. The results revealed that all the tested samples used in the present study pocesses antimicrobial and antifungal activity against tested clinical bacteria and fungi. The Ethanolic extracts of Momordicaaugustisepala leaf showed higher activities against all the tested microorganisms with Zone of Inhibition (ZI) as follows: Candida albicans $(26 \pm 1.6 \mathrm{~mm})$, Pseudomonas aeruginosa $(29 \pm 2.0 \mathrm{~mm})$, Escherichia coli $(28 \pm 1.8 \mathrm{~mm})$, Staphylococcus aureus $(28 \pm 1.9 \mathrm{~mm})$ and Klebsiellapneumoniae $(27 \pm 1.7 \mathrm{~mm})$. The stems of Momordicaaugustisepala showed the following inhibitory zone, Candida albicans $(30 \pm 4.3 \mathrm{~mm})$, Pseudomonas aeruginosa $(27 \pm 3.8 \mathrm{~mm})$, Escherichia coli $(25 \pm 3.3 \mathrm{~mm})$, Staphylococcus aureus $(27 \pm 4.4 \mathrm{~mm})$ and Klebsiellapneumoniae $(25 \pm 3.2 \mathrm{~mm})$. The ethanol extracts showed a very effective inhibition against all the tested organisms compared to the standard of clinical laboratory standard institute (CLSI). From Table 5, plant extract of MAL and MAS in ethanol showed inhibitory concentration of $0.16 \mathrm{mg} / \mathrm{ml}, 0.15 \mathrm{mg} / \mathrm{ml}$ and $0.16 \mathrm{mg} / \mathrm{ml}$ of fungi $C$. albicans, whereas the bacteria showed an inhibitory concentration ranging from $0.10 \mathrm{mg} / \mathrm{ml}$ to $0.23 \mathrm{mg} / \mathrm{ml}$. The antimicrobial test revealed the activities of the tested microorganisms at different concentrations against the extracts of MAL and MAS with ethanol as solvent. It was observed that, the results showed more potent inhibition effects against all the tested microbes, at concentration of 50 $\mathrm{mg} / \mathrm{ml}$. This inhibitory zone of $26 \mathrm{~mm}, 29 \mathrm{~mm}, 28 \mathrm{~mm}, 28$ $\mathrm{mm}$ and $27 \mathrm{~mm}$, and $30 \mathrm{~mm}, 27 \mathrm{~mm}, 25 \mathrm{~mm}, 27 \mathrm{~mm}$ and 25 $\mathrm{mm}$ for $C$. albicans, $P$. aeruginosa, E. coli, $S$. aureus and $K$. pneumonia respectively. It was clear from the results that the ethanol extracts exhibited pronounced activities against tested microorganism. These results to show that the active ingredients of these plant parts were better extracted with ethanol than other solvents from the study according to [17] and [18]. The ethanol extracts contain alkaloids, coumarins and tannins, the presence of coumarins and tannins have antibacterial and antifungal properties. Also [19] and [20] found that ethanol as a solvent was more efficient and effective than any other solvents in extracting phytochemical constituents from plant materials. This shows that ethanol is the most suitable in extracting phyto-constituents from plant materials because of its polar nature. In general, the activities of the plant extracts against the tested bacteria and fungi culture used in this study have shown that the plant extracts possess good biological activity compared with standard antibiotics. From the results, Inhibitory Concentration (IC) for bacteria and fungi range between 0.10 and $0.23 \mathrm{mg} / \mathrm{ml}$ when tested with ethanol extracts of the plants of study. According toIrobi, Bamba and Caceres, various investigations have demonstrated that the extracts of the leaves of $C$. odorata at low concentrations (from 0.1 to 5 $\mathrm{mg} / \mathrm{ml}$ ) inhibited the growth of Pseudomonas aeruginosa, E. coli, S. aureus and Neisseria gonorrhea [21-23]. Also [24] and [25] established the effect of some microorganisms on plant extracts, and their antimicrobial effect was confirmed due to the occurrence of triterpenoids, phenolic compounds, caroteniods, steroids, valavinoids, ketones, tetratriterpenoids and azadirachtin. The minimum inhibitory concentration of $E$. coli is known for its antimalaria, antiameobic and allelopathic properties [26-28]. Therefore, the antimicrobial activity of ethanol extracts of this plants suggested its efficiency and usage in the treatment of various infectious diseases which could be caused by fungi and bacteria like Candidiasis, Taeniasis, Aspergillosis, Cryptococcus Neoformans, Blastormycosis and Sporotricosis also, as well as Syphilis, Gonorrhea, Peptic Ulcer, Impetigo, Meningitis, Urinary Tract Infection, Tetanus, Botulism, Cholera, Samonellosis, Chlamydia, Influenza, Conjunctivitis and Shigellosis. The antimicrobial properties of MAS and MAL were tested against five clinical bacteria isolates: Escherichia coli, Klebsiellapneumoniae, Staphylococcus aureus, Pseudomonas spp. and Serratiamarcescens, using the modified liquid culture method. The bacteria isolates were inoculated and incubated at $37^{\circ} \mathrm{C}$ for 24 hours. Then, they were adjusted with 0.5 McFarland standards and were 
observed at $600 \mathrm{~nm}$ in a UV-Vis Spectrophotometer. The ethanol extracts ofMAL and MAS of the plant $(1 \mathrm{ml}$ each of gradient concentration from $0.25 \mu \mathrm{g} / \mathrm{ml}, 0.50 \mu \mathrm{g} / \mathrm{ml}, 0.75$ $\mu \mathrm{g} / \mathrm{ml}$ and $1.00 \mu \mathrm{g} / \mathrm{ml}$ ) were added into the test tubes containing $5 \mathrm{ml}$ of peptone water medium. An aliquot of $1 \mathrm{ml}$ of the five tested bacterial suspensions was separately inoculated into each tube and incubated at $37^{\circ} \mathrm{C}$ for 24 hours. Positive control experiment contained $1 \mathrm{ml}$ of each bacteria suspension without adding the ethanol extracts. The negative control contains the $5 \mathrm{ml}$ of peptone water medium of the MAS and MAL and the absorbance were obtained. The growths of the bacterial isolates were measured as optical density (OD) at 600nm using UV-Visible spectrophotometer. The percentage growth inhibition of reduction was estimated. It was observed that, at $1.00 \mu \mathrm{g} / \mathrm{ml}$, theMAL inhibited all tested microorganisms as listed below: Escherichia coli $81 \%$, Klebsiellapneumoniae 80\%, Staphylococcus aureus 78\%, Pseudomonas spp $84 \%$ and Serratiamarcescens; $82 \%$. Furthermore, MAS isolated extracts of Escherichia coli were inhibited at 82\%, Klebsiellapneumoniae; 80\%, Staphylococcus aureus 67\%, Pseudomonas spp. 73\% and
Serratiamarcescens $78 \%$. It was observed from the results above that, the activities of antimicrobial properties of MALand MAS tested against five clinical isolates were active at $1.00 \mu \mathrm{g} / \mathrm{ml}$ and more potent against the microorganisms compared to the value of the standard antibiotic used. Table 6 and 7 showed the results of estimation of the in-vitro anti-inflammatory activities through the inhibition of protein albumin denaturation of $M$. angustisepala leaf and stem that was studied using inhibition of albumin denaturation [29] and [30]. The reaction mixture consisted of test extracts and 1\% aqueous solution of bovine albumin fraction, $\mathrm{pH}$ of the reaction mixture was adjusted using small amount of $1 \mathrm{~N}$ hydrochloric acid $(\mathrm{HCl})$. The sample extracts were incubated at $37^{\circ} \mathrm{C}$ for 20 minutes before heated to $51^{\circ} \mathrm{C}$ for 20 minutes. After cooling the samples, the turbidity was measured at $660 \mathrm{~nm}$ (UV/ Visible Spectrophotometer Jenway $6305 \mathrm{~m}$ model). The experiment was performed in triplicate. The Percentage inhibition of protein denaturation was calculated as follows:

$$
\text { ntageinhibition }=\frac{\text { AbsorbaneofControl }- \text { AbsorbanceofSample }}{\text { AbsorbanceofControl }} \times 100 \% \text {. }
$$

The results of estimation of in-vitro anti-inflammatory activities through the inhibition of protein albumin denaturation of M. Angustisepala leaf and Stemthat was studied using the inhibition of albumin denaturation procedure according to [31, 29] and [30], followed with minor modifications. The experiment was performed in triplicate, and the result showed that the plants under study possess anti-inflammatory properties. From the results, maximum inhibition of $86.6 \%$ was recorded at $500 \mu \mathrm{g} / \mathrm{ml}$ for MAS and $89.3 \%$ for MAL at the same concentration. Also, a standard anti- inflammation drug aspirin (Analgesic Drug) showed maximum inhibition concentrations of $85.9 \%$ $500 \mu \mathrm{g} / \mathrm{ml}$ compared with standard. The results above indicated that, the ethanol extracts of the plants of studies possess anti-inflammatory properties; these activities may be due to the presence of secondary metabolite compounds such as alkaloids, flavonoids, tannins, steroids, and phenols. The extract fractions from the plants of study may serve as free radical inhibitors or scavengers or acting possibly as primary oxidants and inhibited the heat induced albumin denaturation. These study gives an idea of the compounds present in the plant MAL and MAS, and can be used as pilot compounds for a scheme of potent anti-inflammatory drug which can be used to cure of various diseases such as inflammation, cancer, aging and neurological disorder.
Table 2. Qualitative Phytochemical screening for Phytoconstituentsof MAL and MAS

\begin{tabular}{lll}
\hline Phytoconstituents & MAL & MAS \\
\hline & Solvent UsedEthanol & \\
Alkaloids & ++ & ++ \\
Glycosides & ++ & ++ \\
Flavonoids & ++ & ++ \\
Tannins & ++ & ++ \\
Saponins & ++ & ++ \\
Terpenoids & ++ & ++ \\
Phenols & ++ & ++ \\
Steroids & ++ & ++ \\
Anthraquinones & ++ & ++ \\
Reducing Sugar & - & - \\
Phlobatanins & - & - \\
\hline
\end{tabular}

Table 3. Quantitative Phytochemical screening of Phytoconstituentspresent in M. augustisepala leaf (MAL) andStem (MAS) crude extracts.

\begin{tabular}{lll}
\hline \multirow{2}{*}{ Phytochemical } & \multicolumn{2}{l}{ Quantity $(\mathbf{m g} / \mathbf{g})$} \\
\cline { 2 - 3 } & MAL & MAS \\
\hline Saponins & $0.3433 \pm 0.24$ & $0.3466 \pm 0.03$ \\
Tannins & $0.6667 \pm 0.02$ & $0.2270 \pm 0.13$ \\
Alkaloids & $0.2370 \pm 0.04$ & $0.2467 \pm 0.02$ \\
Phenolic & $0.3967 \pm 0.12$ & $0.2800 \pm 0.03$ \\
Flavonoids & $0.5300 \pm 0.04$ & $0.4260 \pm 0.02$ \\
\hline
\end{tabular}

Table 4. Antimicrobial potentials of the plant extracts showing their zones of inhibition at $50 \mu \mathrm{g} / \mathrm{ml}$.

\begin{tabular}{|c|c|c|c|c|c|c|}
\hline \multirow{2}{*}{ Samples } & \multirow{2}{*}{ Extracts } & \multicolumn{5}{|c|}{ Test isolates / Zones of inhibition } \\
\hline & & C. albicans (mm) & P. aeruginosa $(\mathrm{mm})$ & E. $\operatorname{coli}(\mathrm{mm})$ & S. aureus $(\mathrm{mm})$ & K. pneumonia (mm) \\
\hline MAL & EtOH-MAL & $26 \pm 1.6$ & $29 \pm 2.0$ & $28 \pm 1.8$ & $28 \pm 1.9$ & $27 \pm 1.7$ \\
\hline MAS & EtOH-MAS & $30 \pm 4.3$ & $27 \pm 3.8$ & $25 \pm 3.3$ & $27 \pm 4.4$ & $25 \pm 3.2$ \\
\hline CLSI & Streptomycin & $25 \mathrm{~mm}$ & $22 \mathrm{~mm}$ & $23 \mathrm{~mm}$ & $18 \mathrm{~mm}$ & $17 \mathrm{~mm}$ \\
\hline
\end{tabular}

Control Antibiotics used: Streptomycin

EtOH-MAL: Ethanol Crude extract ofMomordicaangustisepala leaf

EtOH-MAS: Ethanol Crude extract ofMomordicaangustisepala stem 
Table 5. Zone inhibition of ethanolic extracts at $0.1 \mathrm{mg} / \mathrm{ml}$.

\begin{tabular}{lllllll}
\hline \multirow{2}{*}{ Samples } & \multirow{2}{*}{ Extract } & \multicolumn{6}{l}{ Test Isolate / Zone of inhibition at $\mathbf{0 . 1}(\mathbf{m g} / \mathbf{m l})(\mathbf{m m})$} & S. aureus & K. pneumonia \\
\cline { 2 - 6 } & & C. albicans & P. aeruginosa & E. coli & $23 \pm 0.03$ & $10 \pm 0.03$ \\
\hline MAS & EtoH-MAS & $15 \pm 0.01$ & $18 \pm 0.04$ & $19 \pm 0.04$ & $22 \pm 0.02$ & $11 \pm 0.01$ \\
MAL & EtoH-MAL & $16 \pm 0.02$ & $19 \pm 0.01$ & $21 \pm 0.02$ & \\
\hline
\end{tabular}

EtOH-MAL: Ethanol Crude extract of Momordicaangustisepala leaf

EtOH-MAS: Ethanol Crude extract of Momordicaangustisepala stem

Table 6. Interpretation of spectra for MAL Pure Compound.

\begin{tabular}{llll}
\hline Absorption Bands & Type of Vibrations & Frequency of Vibration & \\
\hline OH (Hydrogen bonded) & Stretching & $3404.74 \mathrm{~cm}^{-1}$ & \\
=C-H Alkenes & Stretching & $3053.52 \mathrm{~cm}^{-1}$ & \\
C-H Aliphatic & Stretching & $2928.21 \mathrm{~cm}^{-1}$ & Stretching \\
C=C-C Alkenes & Stretching & $1716.16 \mathrm{~cm}^{-1}$ & $1716.16 \mathrm{~cm}^{-1}$ \\
C $=$ O of Ester & Stretching & $1730.15 \mathrm{~cm}^{-1}$ & \\
\hline
\end{tabular}

Table 7. Interpretation of spectra for the isolated compound.

\begin{tabular}{ll}
\hline Absorption Bands & Type \\
\hline OH (Hydrogen bonded) & Str \\
=C-H Alkenes & St \\
C-H Aliphatic & Strt \\
C=C-C Alkenes & St \\
- $\mathrm{CH}_{3}$ of Methylene & St \\
\hline & \\
& \\
& \\
\end{tabular}

F. Solani (control)

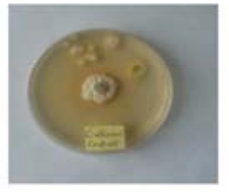

C. albican (control)

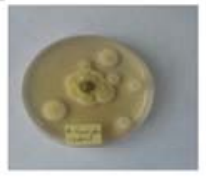

A. fumigatus (control)

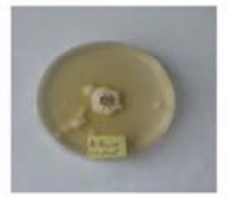

A. flavus (control)

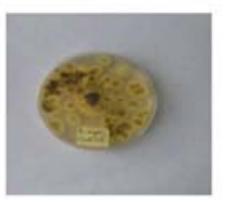

A.niger (control)

Type of Vibration
Stretching
Stretching
Stretching
Stretching
Stretching

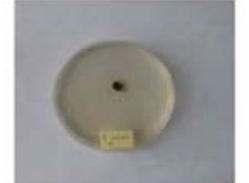

MAS

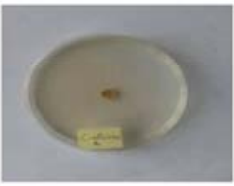

MAS

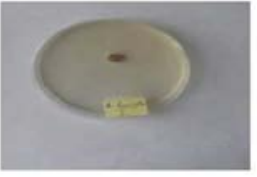

MAS

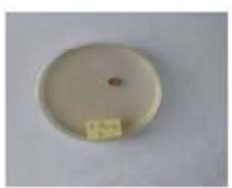

MAS

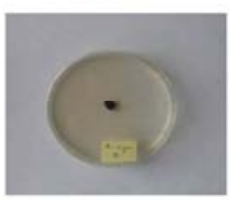

MAS
Frequency of Vibration

$3378.15 \mathrm{~cm}^{-1}$

$3053.52 \mathrm{~cm}^{-1}$

$2928.21 \mathrm{~cm}^{-1}$

$1616.44 \mathrm{~cm}^{-1}$

$1377.03 \mathrm{~cm}^{-1}$

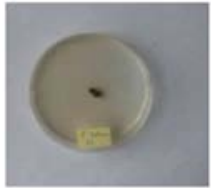

MAL

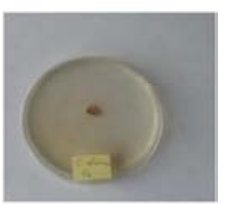

MAL

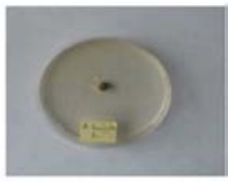

MAL

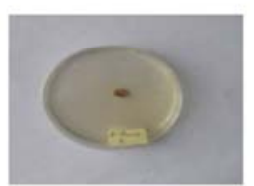

MAL

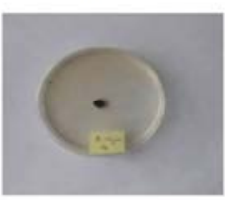

MAL

Figure 2. Antimicrobial screening ofethanolic extracts of MAL and MAS against some selected fungi (F. solani, C. albican, A. fumigatus, A. flavus and A. niger) by disk diffusionmethods. 

Momordicaaugustisepala Seed and Stem Species Grown in Nigeria

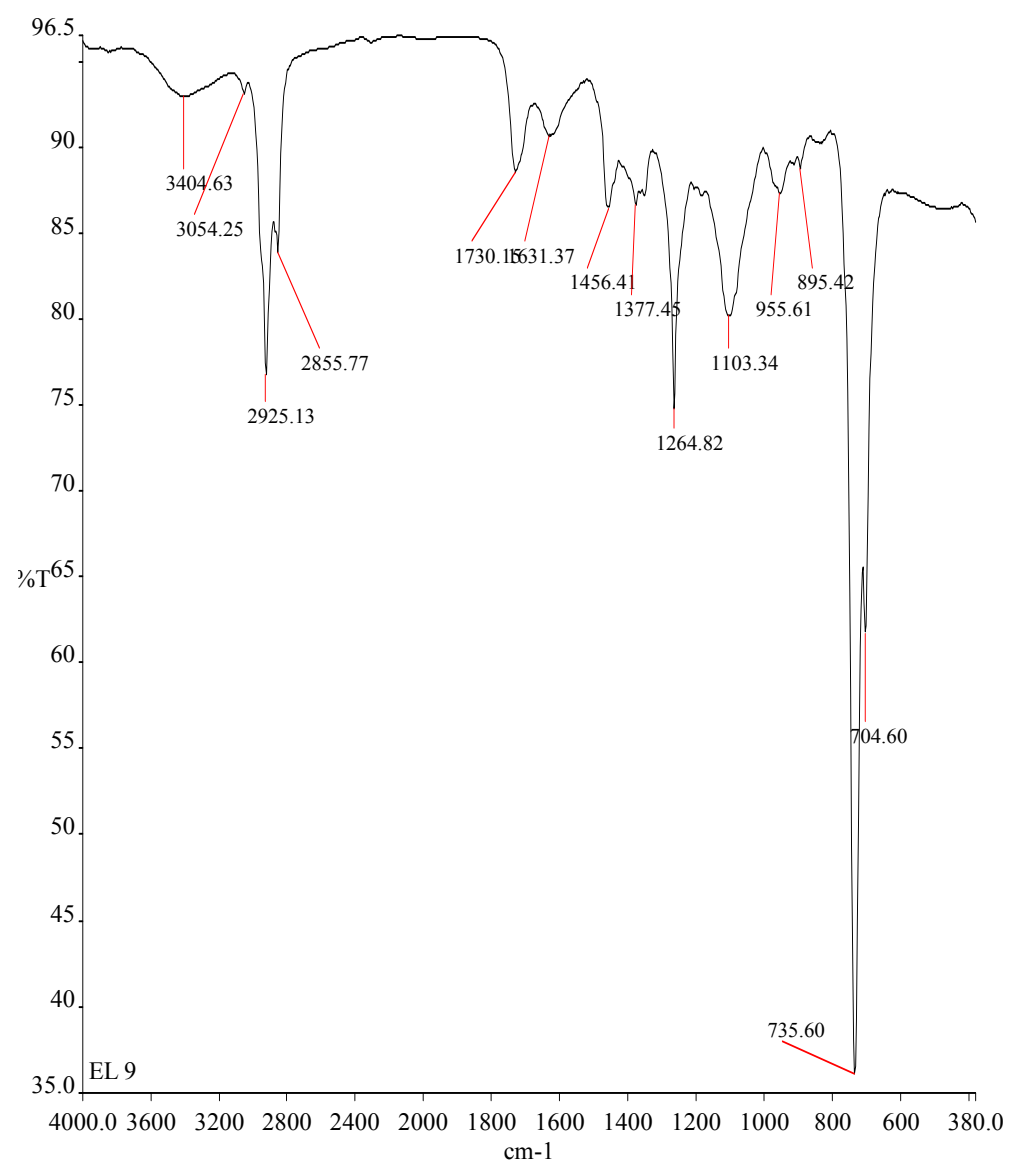

Figure 3. FTIR spectral of the MAL Pure compound from the plants of study.

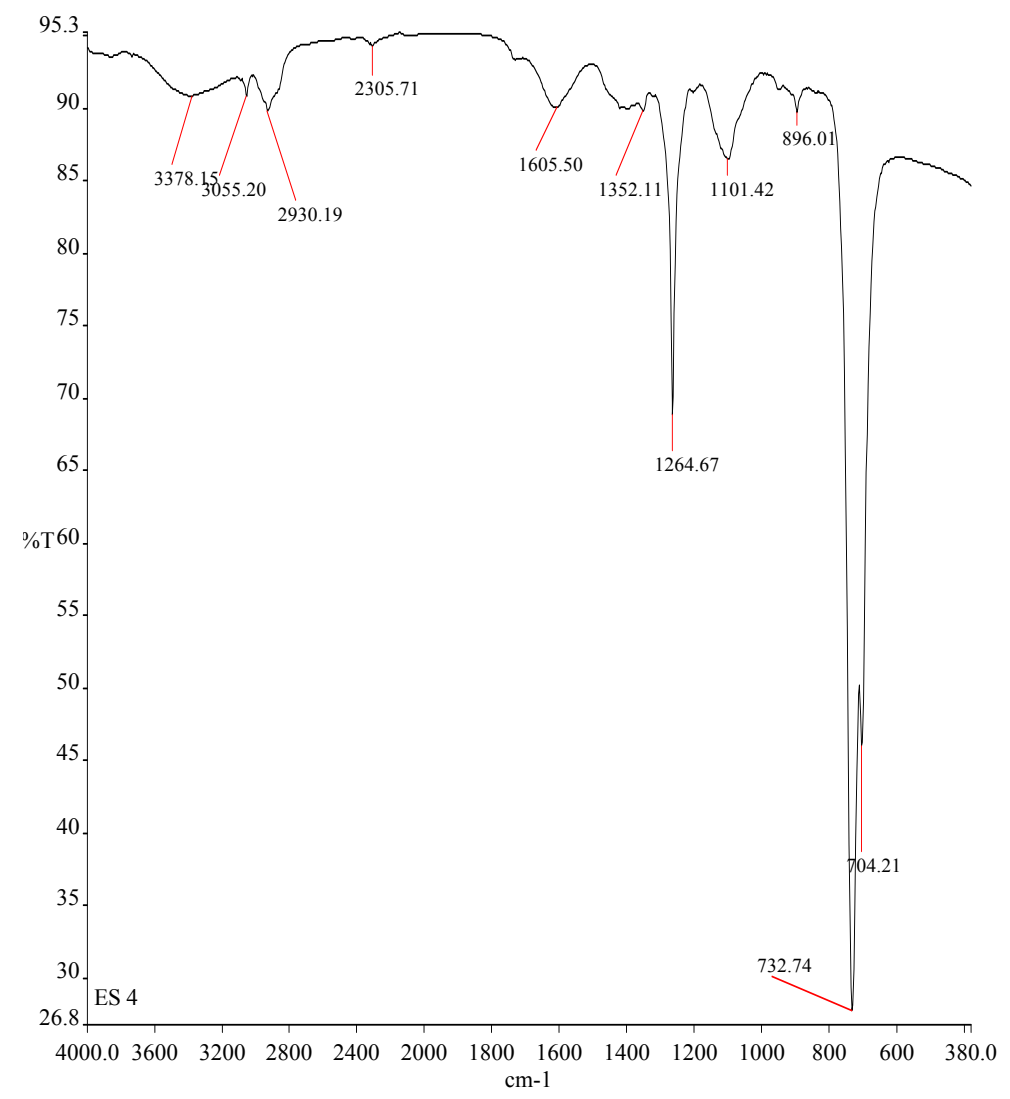

Figure 4. FTIR spectral of theMAS Pure compound from the plants of study. 
Table 8. Invitro investigation of anti-inflammatory activities through the inhibition of albumin denaturation of Momordicaaugustisepala leaf.

\begin{tabular}{llll}
\hline Treatment & Concentration $(\mu \boldsymbol{g} / \mathbf{m l})$ & Absorbance $(660 n m)$ & Protein inhibition denaturation $(\%)$ \\
\hline Control & Nill & $0.29 \pm 0.002$ & Nill \\
EtOH-MAL & 100 & $0.151 \pm 0.004$ & 49.5 \\
EtOH-MAL & 200 & $0.134 \pm 0.001$ & 55.2 \\
EtOH-MAL & 300 & $0.105 \pm 0.002$ & 64.9 \\
EtOH-MAL & 400 & $0.071 \pm 0.003$ & 76.3 \\
EtOH-MAL & 500 & $0.032 \pm 0.003$ & 89.3 \\
Exuprin & 500 & $0.042 \pm 0.001$ & 85.9 \\
\hline
\end{tabular}

EtOH-MAL: Ethanol Isolated extract of Momordicaangustisepala leaf

EtOH-MAS: Ethanol Isolated extract of Momordicaangustisepala stem

Table 9. Invitro investigation of anti-inflammatory activities through the inhibition of albumin denaturation of Momordicaaugustisepala stem.

\begin{tabular}{llll}
\hline Treatment & Concentration $(\mu \boldsymbol{g} / \mathbf{m l})$ & Absorbance $(660 n m)$ & Protein inhibition denaturation $(\%)$ \\
\hline Control & Nill & $0.299 \pm 0.002$ & Nill \\
EtOH-MAS & 100 & $0.191 \pm 0.044$ & 36.1 \\
EtOH-MAS & 200 & $0.161 \pm 0.029$ & 46.1 \\
EtOH-MAS & 300 & $0.109 \pm 0.022$ & 63.5 \\
EtOH-MAS & 400 & $0.048 \pm 0.001$ & 83.9 \\
EtoH-MAS & 500 & $0.040 \pm 0.001$ & 86.6 \\
Exuprin & 500 & $0.042 \pm 0.001$ & 85.9 \\
\hline
\end{tabular}

EtOH-MAL: Ethanol Isolated extract of Momordicaangustisepala leaf

EtOH-MAS: Ethanol Isolated extract of Momordicaangustisepala stem

\section{Conclusion}

Phytochemical results from the ethanolic extracts of $M$. augustisepala leaf and stemhave shown that the medicinal (antibacterial and antifungal) properties of this plants depend on the presence of certain active ingredents such as Alkaloids, Glycosides, flavonoids, terpenoids, Tannins, Saponins, Phenols, Steroids, Anthraquinones, Reducing Sugar and Phlobatanins, which have been known to beresponsible for their medicinal, antimicrobial and antioxidant properties which account for their uses in traditional medicine for the treatment of different infections.

Biological activities of the M. augustisepala leaf and stem demonstrated a broad spectrum of antibacterial and antifungal activities which help to discover new chemical classes of antibiotic substances that could serve as selective agents for infectious diseases, chemotherapy and control. The potency of these plants against certain microorganisms suggests their potential to be used as an alternative therapeutic agent in the face of antibiotic resistance.

In this study, ethanolic extracts of M. augustisepala leaf and stems contain anti- inflammatory properties. These activities may be due to the presence of secondary metabolite compounds such as alkaloids, flavonoids, tannins, steroids phenol and terpenoidsetc, which givean idea that the compound of the plant $M$. augustisepala leaf and stemcan be used as a lead compound for designing a potent antiinflammatory drug which can be used for the treatment of various diseases such as cancer, neurological disorder, aging, inflammation, congestive heart failure, lowering of cholesterol levels inthe blood, healing of wounds, endotoxemia etc. since they contain various phytoconstituents that are known to treatthe above mentioned diseases.

\section{Recommendation}

It was established from this research that the plants of study M. Augustisepala was proved to possess bioactive compounds of medicinal and pharmacological importance. Therefore, seed and stem of M. Augustisepala plant can be recommended as potential candidates for the treatment of infections, diseases, drug designs and development. Further studies on leaf and stem of $M$. angustisepala are recommended to be carried out to isolate, characterized and elucidate the bioactive compounds useful in pharmaceutical and food industries because this plant shown various compound on thin-layer chromatography (TLC) plates. The novel compounds separated on TLC plates may be responsible for M. Augustisepala leaf and stem in the treatment of various diseases such as cancer, neurological disorder, aging, inflammation, congestive heart failure, lowering of cholesterol levels in the blood, healing of wounds, and so on.

\section{References}

[1] Sen, S., Chakraborty, R., De, B., and Mazumder J. (2009). Pharmacognosy Reviews, 3: 270-279.

[2] Ramchoun, M., Harnafi, H., Alem, C., Benlys, M., Elrhaffari, L., and Amrani, S. (2009). Pharmacognosy Research, 1: 106112 .

[3] Kamboj, V. P. (2009). Oxymatrine Prevents NF-кB Nuclear Translocation and Ameliorates Acute Intestinal Inflammation. Current Science. 78: 35-39.

[4] Njoku, O. V., and Obi C. (2009). phytochemical constituents of some selected medicinal plants. African Journal of Pure and Applied Chemistry. 3 (11): 228-233. 
[5] Williamson, E. M. (2002). Major herbs of Ayurveda, 1st edition. The Dabur research Foundation and Daburayurvet limited, Ghaziabad. 182.

[6] Jigna, P., and Sumitra, C. (2007). Antibacterial and phytochemical studies on twelve species of Indian medicinal plants. African Journal of Biomedical Research 10: 175-181.

[7] Edeoga, H. O, Okwu D. E, and Mbaebie B. O. (2005). Phytochemical constituents of some Nigeria Medicinal Plants. Africa Journal of Biotechnology. 4: 685-688.

[8] Anonymous, (2005). The Wealth of India”, a Dictionary of Indian Raw Materials and Industrial Products. NISCAIR Press Publisher, New Delhi. 4: 408.

[9] Ananya, P., and Sen, S. (2010). Medicinal uses and molecular identification of two Momordica Charantial-a review Electronic Journal of Biology 6 (2): 43-51.

[10] Sofowora, A. (1983). Medicinal Plants and Traditional Medicine in Africa. John Wiley and son Limited. 150-153.

[11] Trease, G. E., and Evans, W. C. (1989). Pharmacognosy. 11th Edition. BrailliarTiridel and Macmillian Publishers, London. 38 (6): 542-552.

[12] Harbone, J. B., (1984). Photochemical Methods. Chapman and Hall, London. 89-131.

[13] Garrod, L. P., Lambert, H. P., Grady, F. O., and Waterworth, P. M. (1981): Antibioresistance of Escherichia coli strains isolated in morocco from chicken with colibacillosis. Journal of Ethnopharmacology. 4 (43) 325-330.

[14] Okwu, D. E., and Iroabuchi, F. (2004). Phytochemical analysis and antimicrobial activity screening of aqueous and ethanolic root extract of Uvariachamaebeavand. Journal of Chemical Societies of Nigeria. 115-221.

[15] Raffauf, R. F. (1996). A guide to their discovery and distribution. Hawkworth Press, Inc. New York Preess 35.

[16] Lutete, T., Kambu, K., Ntondele, D., Cimanga, K., and Luki, N. (1994). Antimicrobial Activity of Tannins. Fitoterapia 653: 267-278.

[17] Okemo, P. O. (1996). Antimicrobial efficacy of selected medicinal plants used by Kenyan Herbal doctors. Ph.D. thesis, Kenyatta University of Nairobi. 73-90.

[18] Hedberg I, Hedberg O, Madati P, Mshigeni KE, Mshiu EN, and Samuelsson G (1983). Inventory of plants used in traditional medicine in Tanzania. II. Plants of the family Dilleniaceae to Opiliaceae Journal of Ethnopharmology 9: 105-128.
[19] Eloff, J. N. (1998). Which extractan should be used for screening and isolation of antimicrobial Components from plants Journal of Ethnopharmacology 60: 1-8.

[20] Cowan, M. M. (1999). Plant products as antimicrobial agents. Clinical Microbiolgy. 12: 564-582.

[21] Irobi, O. N., Duguid, J. A., Marmion, B. P., and Swain R. H. A. (1992). Bactericidal properties of crude extracts of Mitracarpusvillosus. Journal of Ethnopharmacology 1: 233-266.

[22] Bamba, D., Bessiere J. M., Marion L, Pelissier Y, and Fouraste I (1993). Essential oil of Eupatorium odoratum. Plant Medicine 59: 184-185.

[23] Caceres A, Menendez H, Mendez E, Cohobon BE, Samayoa E, Jauregui E, and Peralta Carrillo G. (1995). Antigonorrheal activity of plants used in Guatemala for the treatment of sexually transmitted diseases Journal Ethnopharmacology 48 (2): $85-88$.

[24] Almas, K. (1999). The antimicrobial effects of extracts of Azadirachtaindica (Neem) and Salvadorapersica (Arak) chewing sticks. Indian Journal Denttal Research 10: 23-26.

[25] Kraus, W. (1995). In the Neem Tree: Source of Unique Natural products for Integrated Pest management, Medicine, Industry and other purposes. 35-88.

[26] Hopper, M, Kirby GC, Kulkarni MM, Kulkarni SN, Nagasampagi BA, O’Neill MJ, Philipson JD, Rojatkar SR, and Warhurst DC, (1990). Antimalarial activity of parthenin and its derivatives. Europian Journal of Medicinal Chemistry. 25: 717-723.

[27] Bhutani, K. K. and Sharma, G. L. (1998). Plant Based Antiamoebic Drugs; Part II. Amoebicidal Activity of Parthenin Isolated from Partheniumhysterophorus. Plant Medicinal. 54: 120-121.

[28] Kanchan, S. D. (1975). Growth inhibitions from partheniumhysterophorous. linn current Science. 44: 358-559.

[29] Sakat, S., Juvekar A. R., and Gambhire, M. N. (2010). In vitro antioxidant and anti-inflammatory activity of methanol extract of Oxalis corniculata Linn. International Journal of Pharma and Pharmacological Sciences 2 (1): 146-155.

[30] Leelaprakash., G. J., Rose C., Gowtham B. M., Javvaji P. K., and Prasad. S. A. (2011). Invitroantimicrobial and antioxidant activity of Momordicacharantia leaves. Pharmacophore: 2 (4) 244-252.

[31] Mizushima, Y., and Kobayashi, M. (1968). Interaction of antiinflammatory drugs with serum preoteins, especially with some biologically active proteins. Journal of Pharmacy Pharmacological 20: 169-173. 